\title{
Gonadal Development Stages of Wild Male Golden Mahseer, Tor putitora from Nainital Region of Uttarakhand, India
}

\author{
N. Shahi*, J. Pandey, S. K. Mallik, D. Sarma and P. Das \\ Directorate of Coldwater Fisheries Research, Industrial Area, Bhimtal, (Uttarakhand), India - 263136
}

\begin{abstract}
Golden mahseer, Tor putitora is an endangered fish of mid-Himalayan regions of India. It has good potential as aquaculture species for hill aquaculture, due to its high market demand. But the major constrains on introduction of this fish for aquaculture is its inability to breed in captivity and slow growth rate. Therefore, studies were carried out on its breeding biology to captive breed this fish for sustainable seed production. However, detailed study on reproductive pattern of adult golden mahseer is very limited. Therefore, in the present study, we have developed a macroscopic grading system for golden mahseer testes, which shows the testes development stages during the breeding season, which lasts from May-September in Bhimtal and Sattal lakes. The golden mahseer were sampled from February - September 2014, from Bhimtal and Sattal lakes. Altogether, 48 samples were collected during the sampling period. Based on macroscopic observation, the maturation stage of the testes was divided into five developmental stages: Immature (I), early spermatogenic (II), late spermatogenic (III), matured (IV) and spent (V).
\end{abstract}

Keywords: Tor putitora, Reproduction, Maturity, Testes.

\section{Introduction}

Golden mahseer, Tor putitora is an important food and game fish of mid -Himalayan regions of northern India. This fish has high demand as food, due to its good taste and nutritional content. Moreover, it is an excellent game fish, because of its fierce fighting nature (Jha and Rayamajhi, 2010). To fulfill the growing demand of fish eaters, indiscriminate fishing has been taken place over the last few decades, which has declined the natural population of $T$. putitora in its habitat. Moreover, construction of hydro-electric dams and habitat destruction has further reduced its population, and thus this species is now, listed under red data book as an endangered fish species (Khan and Sinha, 2000).

To revive the population of this indigenous fish, several attempts were undertaken (Das and Joshi, 1994). Ranching in natural water bodies and captive breeding of this fish has been initiated by central and state government departments. However, like many other fishes, $T$. putitora does not attain complete gonadal maturity in captivity, the seed production still depends on matured brooders collected from wild (Masuda and Bastola, 1984). Collection of brooders from wild is not a sustainable means of seed production, therefore, now attempts to breed this fish in captivity by using hormones have been given consideration (Shrestha et al., 1990). But, to captive breed this fish, it is important to know about its reproductive cycle and maturity stages.

Studies of gonad morphology at anatomical levels have long been done by fish biologists to identify reproductive cycles and to determine size-at-maturity. In fisheries, the determination of the reproductive state of a fish population in a specific area and time plays a very significant role, because these parameters are closely related to stock productivity and are the basis of many regulatory measures (Hunter and Macewicz, 2003). Until recently, the reproduction of $T$. putitora had been 
studied sporadically on the basis of breeding biology with limited sample size (Sunder and Joshi, 1977). Macroscopic maturity scales of fish ovaries and testes are among the most frequently used indexes in assessments of fish reproductive condition (Hunter and Macewicz, 2003). This method is fast and inexpensive and can detect major reproductive events such as spawning season.

Generally, the majority of the macroscopic studies related to fish reproduction have been carried out for female, with sporadic studies being done on male reproduction (Parenti and Grier, 2004; Lowerre-Barbieri et al., 2011). But the males may have different reproductive parameters from females such as a different period of spawning seasons and a different size and age at maturity (Lowerre-Barbieri et al., 2011). Therefore, the knowledge of the reproductive biology of male fish is very significant for adopting any breeding and management measures.

In the present study, the detailed description of $T$. putitora testes developed at macroscopic (anatomical) level was carried out during the breeding season. The seasonal variability of gonad characteristics was used to build an anatomical scale.

\section{Materials and Methods}

\section{Sampling of Golden Mahseer}

From February to September 2014, 48 male $T$. putitora samples (Fig. 1) were collected from Bhimtal and Sattal lakes of Nainital district of

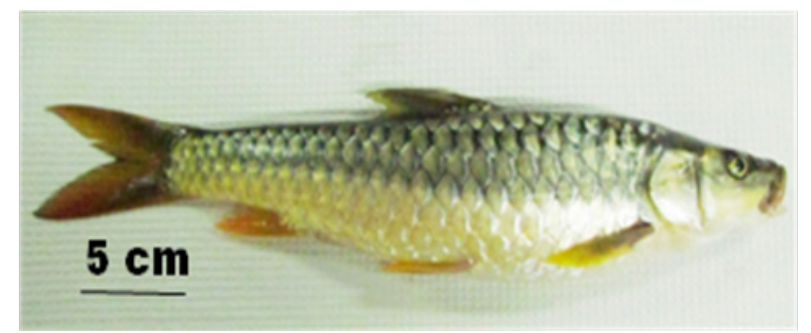

Fig. 1 Matured male golden mahseer from Sattal Lake of Nainital.
Kumaun region of Uttarakhand. All the fishes were taken from local fisherman. The average total length and weight of the fishes were $32.78 \pm$ $9.87 \mathrm{~cm}$ and $380 \pm 68.90 \mathrm{~g}$, respectively. The collected fishes were brought to the wet laboratory and after measuring morphometric parameters, sacrificed for gonad analysis. In the study, fishes above the age of 3.5 years were included for analysis and the age of the fishes were determined by counting the number of rings on their scale of dorsal region. All the fish were anaesthetized by clove oil (50 $\mu \mathrm{l} / \mathrm{L}$ of water) before sacrifice. The gonads were collected for analysis by macroscopic characteristics.

\section{Macroscopic Analysis}

The macroscopic analysis and classification of the testes was carried out based on color, fullness, thickness, extrusion of milt, presence of blood spots and shape and length of gonad (Table 1).

\section{Results and Discussion}

The male fish had slender body and milky white milt oozes freely in matured golden mahseer. The testes of the $T$. putitora were divided into five gonadal developmental stages based on macroscopic observations (Fig. 2A-2E).

Immature (I) Testes: asymmetrical thin, elongated, paired with smooth edges and pale white in color (Fig. 2A).

Early spermatogenic (II) Testes: elongated, slightly thicker, off white and translucent (Fig. 2B) Blood spot were visible on surface.

Late spermatogenic (III) Testes: asymmetrical, pinkish white, opaque, lobular, enlarged (Fig. 2C) and larger in volume. Milt could not be striped at this stage.

Spermiation (IV) Testes: enlarged, massive, milky white, soft and anterior part is filled with white color milt (Fig. 2D). Viscous fluid present in the anterior part. blood vessels spread on the surface. Testes occupy almost entire length 
Table 1 Major characteristics used in the macroscopic analysis of Tor putitora testes

\begin{tabular}{|l|l|}
\hline Feature & Classification levels for testes \\
\hline Color of the gonad & Grey, Brown, Red, Orange, White \\
\hline Fullness & Empty looking, half full and full \\
\hline Thickness & Thick, medium thick and thin \\
\hline Pressure on abdomen & Semen released on gentle pressure to abdomen, Semen not released on pressure \\
\hline Blood spots on gonad & Conspicuous, inconspicuous \\
\hline Shape of the gonad & Triangular, rectangular, circular or too thin to characterize \\
\hline Length of the gonad & $\begin{array}{l}\text { Cover the entire length of the body cavity, half the length of the body cavity, less than half the } \\
\text { length of the body cavity }\end{array}$ \\
\hline
\end{tabular}

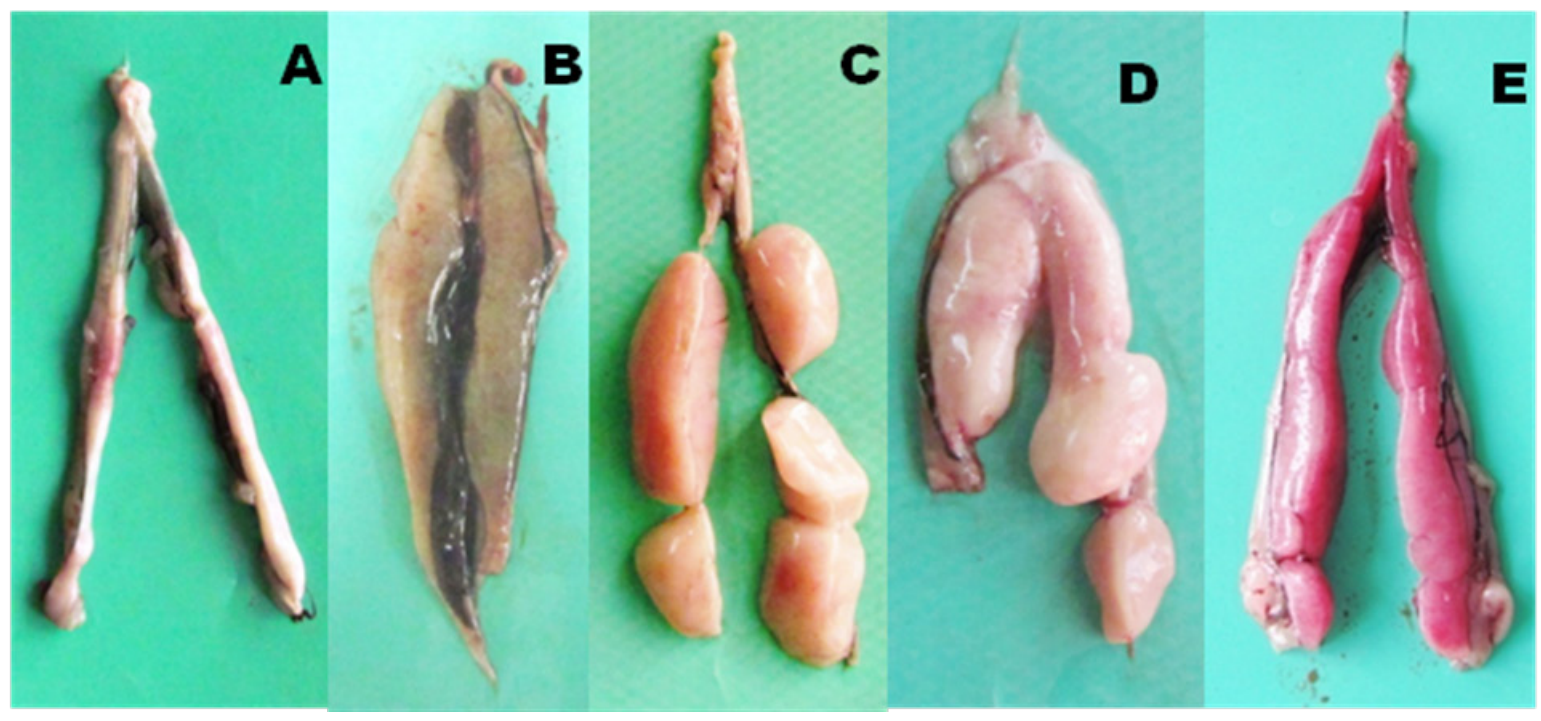

Fig. 2 Macroscopic appearance of Tor putitora testes collected from Bhimtal and Sattal lakes of Nainital district. A- anatomical class I; B- anatomical class II; C- anatomical class III; D- anatomical class IV; E- anatomical class V.

of the body cavity. Milt could be stripped from more than $70 \%$ of the males in this stage.

Post-spawning (V) Testes: in regression, flabby, blood red and deflated sacs (Fig. 2E). Milt could not be stripped from any of the male.

In the month of February to March, majority of the male fish were Immature (Fig. 3), where as in the June and July the number of fishes oozing milt increased drastically.

Due to indiscriminate capture of brooders and juveniles and habitat destruction, this fish is assessed as endangered and is in need of immediate conservation efforts to save it from becoming extinct. Golden mahseer productivity is reported to decline in the Tehri Dam in the Garhwal Himalaya, India. The stress on the population is not only because of its overexploitation, but also due to the rise in anthropogenic activities, especially the growing number of hydroelectric dams and irrigation projects which have fragmented and deteriorated its habitat (Jha and Rayamajhi, 2010). The species has the potential for being cultured in 


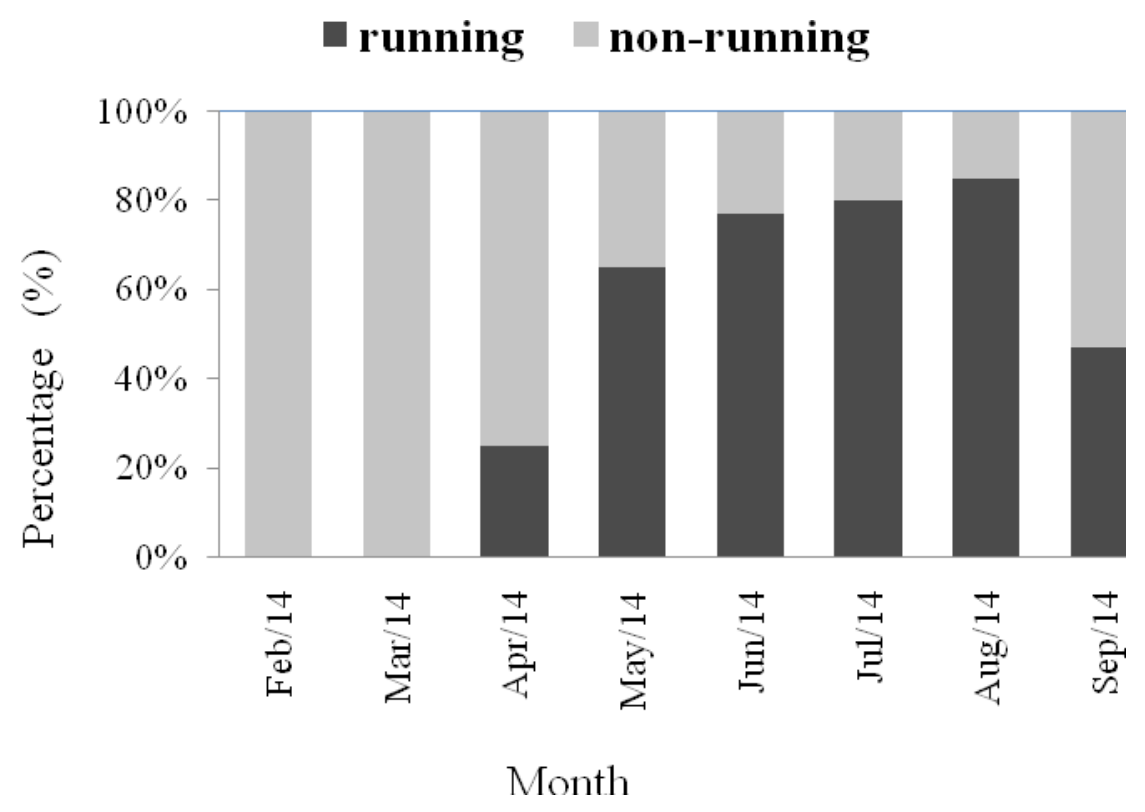

Fig. 3 Proportion of running and non-running males of golden mahseer at different stages of testicular development.

aquaculture ponds and ranched in rivers/artificial channels of Trans-Himalayan region. Strategies for preservation of existing stock by habitat conservation, development of seed production technology for restocking and culture have been undertaken to promote the population.

Several attempts were made to breed this fish in captivity. However, the rate of success was very low, and the collected brooders were mainly from nature. The main hindrance in development of a strategy for captive maturation is that, its gonadal developmental stages were not studied in detail during the breeding season. There are few studies on its breeding biology from nature. So to develop a successful strategy for the captive maturation of this species, it is very essential to know about its gonadal development stages in nature.

Macroscopic study of the gonadal development stages provide information about the extension of the gonad in relation to the body cavity as well as the width of the gonad at the widest point. The maturity stages can be distinguished on size, shape, color and structure of the gonad. In male fish, there is a difference in maturity stages of testes, which occur due to sperm formation. However, color is a more prominent trait in females than males, as the variation in color between testes in different maturity stages is more subtle than for ovaries. The most significant macroscopic characteristics of testes in males are the volume of the testes compared to the body cavity as well as the appearance of the sperm duct and milt. The male reproductive cycle in general exhibit a smoother transition between stages than the female cycle.

In this study, we described the first detailed study of the male reproductive characteristics of wild Tor putitora from lakes of Kumaun region of Uttarakhand. Historically, macroscopic classifications of gonad development had been the major method for reproductive studies of fish, mainly in male reproduction (Gil et al., 2013). In case of golden mahseer, majority of the study is focused on its life cycle, breeding biology, length weight relationship, embryonic development and nutritional requirement (Hora and Mukerjee, 1936; Hora, 1939). Mahseer breeds several times 
during a year (Hora, 1939). T. putitora is known to breed in Himalayan Rivers during August to September (Hora and Mukerjee, 1936). Though the gonadal development stages were studied for tor mahseer, the same was not studied in detail for Himalayan mahseer. The gonadal development stages of the T. putitora were found to be near similar to tor mahseer. Majority of the male fish above the length of $30 \mathrm{~cm}$, captured in the month of June and July were oozing milt. These fishes were more than 3 years old. It indicates that male get mature in monsoon month in this region. It may be due to the lowering in temperature and influx of freshwater, which stimulates their gonadal development. In this study we categorized the reproductive maturation of testes into 5 development stages based on macroscopic observation. This study was performed during the breeding season in Nainital region of Uttarakhand, India.

\section{Acknowledgement}

The authors would like to thank Director ICARDCFR, for providing necessary facility to carry out this work.

\section{References}

Das, P. and Joshi, K. D. (1994) Mahseer conservation present and future. P. Nautiyal (comp. \& ed.): Mahseer: The Game Fish: D3-D9. Rachna, Srinagar, India.

Gil, M. M., Grau, A., Basilone, G., Ferreri, R. and Palmer, M. (2013) Reproductive strategy and fecundity of meagre Argyrosomus regius Asso, 1801 (Pisces: Sciaenidae): implication for restocking programs. Sci. Mar., 77, 105-118.
Hora, S. L. (1939) The game fishes of India VIII. The mahseer or the large scaled barbels of India. J. Bombay. Nat. Hist. Soc., 41, 272-285.

Hora, S. L. and Mukerjee, D. D. (1936) Fishes of eastern Doons, U.P. Rec. Ind. Mus., 38, 139-142.

Hunter, J.R. and Macewicz, B.J. (2003) Improving the accuracy and precision of reproductive information used in fisheries. In: Kjesbu O.S., Hunter J.R., Witthames P.R. (eds), Report of the working group on modern approaches to assess maturity and fecundity of warm- and cold-fish and squids. John Grieg Grafisk AS, Bergen, pp. 57-68.

Jha, B.R. and Rayamajhi, A. (2010) Tor putitora. The IUCN Red List of Threatened Species. Version 2014.1. <www.iucnredlist.org>.

Khan, M.A. and Sinha, M. (2000) Status of Mahseer Fisheries in north and north eastern India with a note on their conservation. J. Inl. Fish. Soc. India., 32, 28-36.

Lowerre-Barbieri, S.K., Ganias, K., Saborido-Rey, F., Murua, H. and Hunter, J.R. (2011) Reproductive timing in marine fishes: Variability, temporal scales, and methods. Mar. Coast. Fish., 3, 71-91.

Masuda, K. and Bastola, K. R. (1984) Breeding of Sahar (Tor putitora, Ham.) using naturally Matured Broods in Tadi River of Central Nepal. Report submitted to the Fisheries Development Division, HMG/Nepal.

Parenti, L.R. and Grier, H.J. (2004) Evolution and phylogeny of gonad morphology in bony fishes. Integr. Comp. Biol., 44, 333-348.

Shrestha, B. C., Rai, A. K., Gurung, T. B. and Mori, K. (1990) Successful artificial induced spawning of Himalayan Mahseer (Tor putitora, Ham.) in Pokhara Valley, Nepal. The Second Asian Fisheries Forum. Asian Fish. Soc.

Sunder, S. and Joshi, C.B. (1977) Preliminary observations on the spawning of Tor putitora (Hamilton) in Anji stream Jammu province. Indi. J. Fish., 24, 153-158. 
